\title{
Recommendations for the use of meningococcal vaccines in South Africa
}

\author{
Susan Meiring ${ }^{a * i}$, Gregory Hussey $^{\mathrm{b}}$, Prakash Jeenac, Salim Parkerd and Anne von Gottberg ${ }^{\mathrm{e}}$ \\ a'Division of Public Health Surveillance and Response, National Institute for Communicable Diseases, a division of the National Health Laboratory \\ Services, Johannesburg, South Africa \\ ${ }^{b}$ Vaccines for Africa Initiative, Institute for Infectious Diseases and Molecular Medicine, University of Cape Town, Cape Town, South Africa \\ 'Department of Paediatrics, University of KwaZulu-Natal, Durban, South Africa \\ ${ }^{d}$ General Practitioner, South African Society of Travel Medicine, Cape Town, South Africa \\ ${ }^{e}$ Centre for Respiratory Diseases and Meningitis, National Institute for Communicable Diseases, a division of the National Health Laboratory \\ Services, Johannesburg, South Africa \\ *Corresponding author, email: susan.meiring@nhls.ac.za

Background: Although meningococcal disease (MD) incidence in South Africa is low, Neisseria meningitidis (NM) causes severe disease that is often life-threatening and can cause long-term disabilities. A quadrivalent protein-conjugated meningococcal vaccine (MCV4) is available, and provides protection against $75 \%$ of disease causing serogroups in South Africa.

Recommendations: We advise vaccination of persons at high risk of meningococcal disease including those with complement deficiency and asplenia; laboratory personnel from reference laboratories who work with NM; and travellers to Saudi Arabia. The need for routine vaccine against meningococcal disease in South Africa is controversial given the current burden of disease. However, due to the high morbidity/mortality of MD we recommend that clinicians consider vaccination of healthy infants and children; HIV-infected persons with a CD4 count > 25\%; students attending college /university /military academies; and miners. Conclusion: Protein-conjugated meningococcal vaccine is preferable to the polysaccharide vaccine given the ability of the protein-conjugated meningococcal vaccine to induce immune memory, allow for booster responses and eliminate carriage of the organism in the person vaccinated.

Keywords: guidelines, meningitis, meningococcal vaccines, Neisseria meningitidis, South Africa, vaccine

\section{Introduction}

Meningococcal disease is a devastating illness with a high mortality rate despite appropriate therapy. Meningococcal conjugate vaccines have become available in South Africa since 2014. The aim of this document is to guide clinicians in decision making regarding when meningococcal vaccine should be used and which vaccine would be most appropriate.

\section{Epidemiology of meningococcal disease in South Africa}

Meningococcal disease is caused by the bacterium, Neisseria meningitidis, which is a Gram negative intracellular diplococcus. Humans are the sole natural host of this infective organism. ${ }^{1,2} \mathrm{Up}$ to $10 \%$ of the population carry N. meningitidis asymptomatically in their nasopharynx and spread the organism from person to person via respiratory droplets. In industrialised countries, teenagers (15-19 years of age) had the highest colonisation rate $(25 \%)_{1}^{3,4}$ whilst in the African meningitis belt carriage was lower and peaked at $5 \%$ in children $5-14$ years of age. ${ }^{5}$

Colonisation with $N$. meningitidis usually confers protection through the production of antibodies to that particular strain. ${ }^{6}$ Infrequently, newly acquired hypervirulent carriage strains are able to invade the mucosa and cause bacteraemia and/or meningitis. Disease onset is often rapid and can become lifethreatening despite appropriate antibiotic therapy. Sequelae ranging from hearing loss, skin scarring, amputations and neurological fall out are evident in approximately $20 \%$ of survivors. $^{7-9}$
Risk factors for acquisition of carriage (which is a prerequisite for disease) include passive smoking, intimate personal contact (kissing), pub attendance, overcrowding, the attendance of mass gatherings and previous antibiotic use. These are all largely behaviour-related and thus may explain the high carriage seen in teenagers and young adults. ${ }^{3}$ Other risk factors for disease include HIV infection, other immune deficiencies (especially of the complement components) and asplenia. ${ }^{10-12}$

Meningococcal disease is endemic in South Africa with sporadic cases occurring throughout the year, usually increasing from May to October. Average incidence in the population over the past decade is 1 per 100000 people, with a peak of 8 per 100000 people in infants. ${ }^{13}$ Over the last decade in South Africa, approximately $17 \%$ of people with meningococcal disease have died, with case fatality ratios increasing with age.

The bacterium, N. meningitidis, is surrounded by a polysaccharide capsule, which is used to classify the organism into 12 serogroups. Six of these 12 serogroups have been found to cause disease in South Africa, with the majority of disease caused by serogroup W, followed by serogroup B. Prior to 2005, serogroup A was South Africa's predominant disease causing serogroup but only a few cases have been detected over the last 3 years (Figure 1).

Since the 2006 peak in meningococcal disease in South Africa, cases are now at an all-time low, despite limited vaccine use. ${ }^{14}$ Meningococcal case-loads are known to wax and wane over periods of 5 to 10 years, therefore South Africa may possibly be on the verge of seeing an increase in meningococcal disease in the near future. 


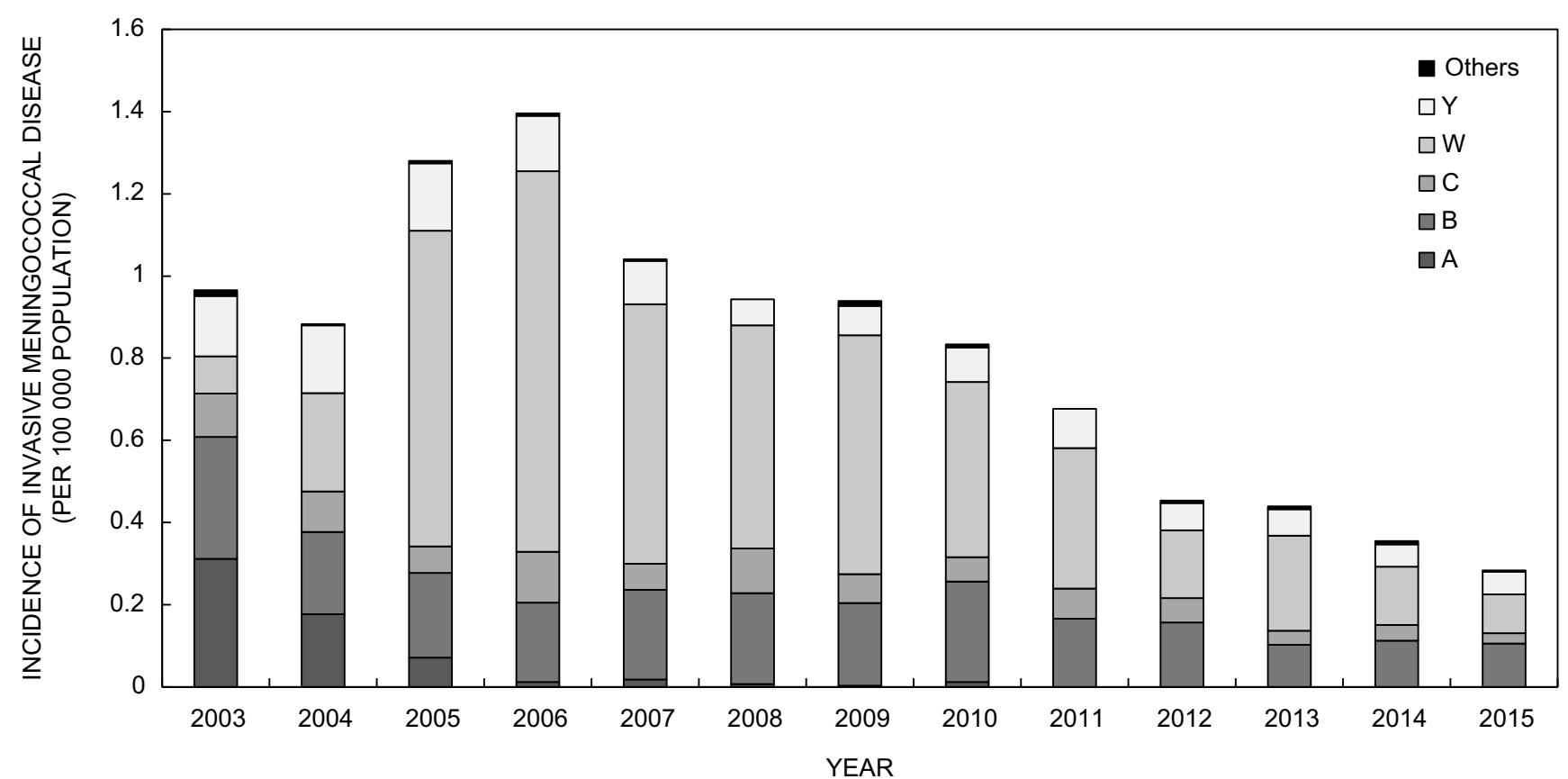

Figure 1: Incidence of invasive meningococcal disease by serogroup, South Africa, 2003-2015 $(n=5118)$.

\section{Meningococcal vaccines registered in South Africa}

Currently there are two types of meningococcal vaccines available in South Africa: a polysaccharide vaccine (Menomune ${ }^{\circledR}$, Sanofi Pasteur (MPSV4)) and a protein-conjugate polysaccharide vaccine (Menactra ${ }^{\circledR}$, Sanofi Pasteur (MCV4)). These are both quadrivalent vaccines targeting the polysaccharide capsules of serogroups $\mathrm{A}, \mathrm{C}, \mathrm{W}$ and $\mathrm{Y}$.

The MPSV4 has until 2014 been the only quadrivalent meningococcal vaccine available in South Africa. This polysaccharide vaccine elicits a T-cell independent immune response and is thus poorly immunogenic in infants and toddlers. Protection is generally limited to 3-5 years. It has been found that repeated doses may confer immunological hyporesponsiveness. ${ }^{15}$ MPSV4 does not eliminate nasopharyngeal carriage and does not induce herd immunity.

MCV4 is a protein-conjugate polysaccharide vaccine (polysaccharides are carried by a protein) that induces both B-cell and T-cell immunity; stimulates immune memory; decreases carriage of the organisms; and allows for booster responses. They are immunogenic in infants and are at present licensed for use in persons from 9 months to 55 years of age. ${ }^{15}$ Persons 2 years and over generally require a single dose and children from 9 months to 23 months require two doses given 12 weeks apart. Recent studies have shown that antibody levels do decline 5 years following vaccination, therefore booster doses are recommended should a person remain at increased risk for disease. ${ }^{16,17}$ MCV4 is safe and immunogenic in HIV-infected children and adults, with a CD4 $>25 \%$, if given in a two-dose schedule. ${ }^{18,19}$

Adverse effects associated with the use of the quadrivalent vaccines are minimal.Vaccine recipients experience mild pain at the injection site for 1-2 days, a low grade fever, headache and/or malaise. There is no increased risk of Guillain-Barre syndrome associated with vaccine use, although vigilance for this adverse effect is essential. ${ }^{20}$

Immunogenicity studies of MCV4 have shown that it is safe and effective to give concomitantly with other childhood vaccines such as measles, mumps, rubella, varicella and the pneumococcal conjugate vaccine. ${ }^{21}$

\section{Recommendations for vaccination}

Although the incidence of meningococcal disease is currently low in South Africa, the consequence of acquiring the disease can be devastating with high morbidity and mortality despite adequate treatment. Ideally, all South Africans should be protected against this disease, even though the risk for acquiring it is low. Certain individuals are at higher risk for acquiring the disease and vaccination is recommended in these persons.

Persons with primary immunological disturbances of the immune system (particularly complement deficiency), on immunosuppressive therapy following solid organ transplant and haemopoetic stem cell transplant, acquired immune deficiency (HIV-infection) or those with functional or anatomic asplenia are considered at high risk, and should be offered routine vaccination. $12,17,22,23$

Other groups at increased risk include those with occupational exposure to meningococci in a microbiology laboratory, persons living in crowded living conditions (school/university students in hostels, army recruits and miners) and those travelling to hyperendemic areas. These groups should be offered routine vaccination. ${ }^{24-26}$

In an outbreak setting where the affected population can be clearly defined and the serogroup associated with the disease is identified and covered by the vaccine, vaccination could be used as a control measure. This does not obviate the need for chemoprophylaxis and can be given up to 4 weeks post exposure..$^{27}$

\section{Recommended vaccination schedule}

The risk for meningococcal disease could change at any time and under different circumstances and thus our recommendations for vaccination, summarised in Table 1, are divided into the following categories: 
The meningococcal vaccine:

\section{i. Should be considered, \\ ii. Is recommended, or \\ iii. Is required}

A MCV4 vaccine targeting serogroup $\mathrm{A}, \mathrm{C}, \mathrm{W}$ and $\mathrm{Y}$ should be considered in children between 9 months and 5 years of age. Justification for this includes: the high disease burden in infants; the higher risk of NM clusters in preschools than secondary schools; and, $75 \%$ of meningococcal disease in South Africa has been caused by serogroup A, C, W and Y (Figure 1) .13,28 Protein conjugate vaccines induce T-cell dependent immune response, stimulating immune memory and inducing mucosal immunity, thus eliminating carriage and are effective in children $<2$ years of age, unlike the polysaccharide vaccines. Serogroup $B$ vaccines are currently not licenced for use in South Africa. Infants 9 months through to 23 months should be given a two-dose primary series with a dosing interval of 12 weeks, while healthy children 2 years and older require just a single primary dose.

Vaccination with MCV4 should be considered in all adolescents and young adults prior to entering their first year of university, college or military training especially if they will be staying in a residence hall. A single primary dose of MCV4 should be given in this instance. A booster dose should be given if meningococcal vaccine had been given more than 5 years previously.

Vaccination with MCV4 should be considered for all mine workers staying in hostels. A single primary dose of MCV4 should be given.

Vaccination with MCV4 is recommended for all reference/research laboratory workers who routinely work with isolates of $N$. meningitidis. Routine laboratory safety measures should continue to be followed when working with this organism.

Vaccination with MCV4 is recommended for all travellers to hyperendemic regions or where epidemics of meningococcus are occurring (e.g. countries of the African meningitis belt). Pilgrims to the Hajj and Umrah, and visitors to Saudi Arabia are required to obtain a quadrivalent vaccine at least 10 days prior to entry into the country. A booster is required if the vaccine has been given beyond the previous 3 years for MPSV4 or previous 5 years for MCV4. ${ }^{29}$

Any person attending a mass gathering (i.e. scout jamborees; sporting event) should consider vaccination with MCV4 prior to commencement of travel.

Table 1: Suggested recommendations of use of meningococcal vaccine in South Africa

\begin{tabular}{|c|c|c|c|c|}
\hline Population Group & Vaccine choice & Recommendation & Primary dosing & Booster \\
\hline \multirow[t]{2}{*}{ Healthy children and infants } & \multirow[t]{2}{*}{$\begin{array}{l}\text { Quadrivalent conjugate vaccine } \\
\text { (MCV4) }\end{array}$} & \multirow[t]{2}{*}{ Should be considered } & $\begin{array}{l}\text { Children } 9 \text { months to } 23 \text { months: } \\
2 \text { doses } 12 \text { weeks apart }\end{array}$ & \\
\hline & & & Children $\geq 24$ months: 1 dose & \\
\hline $\begin{array}{l}\text { Healthy adolescents or young } \\
\text { adults entering university or } \\
\text { college (particularly if staying in } \\
\text { hostels) }\end{array}$ & $\begin{array}{l}\text { Quadrivalent conjugate vaccine } \\
\text { (MCV4) }\end{array}$ & Should be considered & $\begin{array}{l}\text { Single dose prior to entry into } \\
\text { university or college }\end{array}$ & \\
\hline $\begin{array}{l}\text { Military recruits on training or } \\
\text { deployment }\end{array}$ & $\begin{array}{l}\text { Quadrivalent conjugate vaccine } \\
\text { (MCV4) }\end{array}$ & Should be considered & $\begin{array}{l}\text { Single dose prior to commenc- } \\
\text { ing training or deployment }\end{array}$ & $\begin{array}{l}\text { Booster dose required if risk } \\
\text { remains high } 5 \text { years after } \\
\text { primary dose }\end{array}$ \\
\hline Miners & $\begin{array}{l}\text { Quadrivalent conjugate vaccine } \\
\text { (MCV4) }\end{array}$ & Should be considered & Single primary dose & \\
\hline $\begin{array}{l}\text { Research/reference laboratory } \\
\text { workers routinely exposed to } N \text {. } \\
\text { meningitidis }\end{array}$ & $\begin{array}{l}\text { Quadrivalent conjugate vaccine } \\
\text { (MCV4) }\end{array}$ & Recommended & Single primary dose & $\begin{array}{l}\text { Booster dose every } 5 \text { years if risk } \\
\text { remains }\end{array}$ \\
\hline $\begin{array}{l}\text { Travellers to meningitis belt or } \\
\text { other areas where disease is } \\
\text { hyperendemic/epidemic }\end{array}$ & $\begin{array}{l}\text { Quadrivalent conjugate vaccine } \\
\text { (MCV4) }\end{array}$ & Recommended & Single primary dose & $\begin{array}{l}\text { Booster dose every } 5 \text { years } \\
\text { should be considered for re- } \\
\text { peated travel to highly endemic } \\
\text { areas }\end{array}$ \\
\hline $\begin{array}{l}\text { Hajj pilgrims and travellers to } \\
\text { Saudi Arabia }\end{array}$ & Quadrivalent conjugate vaccine & Required & Single primary dose & $\begin{array}{l}\text { A booster dose every } 3 \text { years for } \\
\text { MPSV4 or } 5 \text { years for MCV4 is } \\
\text { required for repeated travel as } \\
\text { per current Saudi regulations }\end{array}$ \\
\hline Attendees of mass gatherings & $\begin{array}{l}\text { Quadrivalent conjugate vaccine } \\
\text { (MCV4) }\end{array}$ & Should be considered & Single primary dose & \\
\hline $\begin{array}{l}\text { Persons with medical conditions } \\
\text { at high risk of acquiring infec- } \\
\text { tion: Complement component } \\
\text { deficiencies }\end{array}$ & $\begin{array}{l}\text { Quadrivalent conjugate vaccine } \\
\text { (MCV4) }\end{array}$ & Recommended & $\begin{array}{l}\text { Two-dose primary schedule } \\
12 \text { weeks apart }\end{array}$ & Booster every 5 years \\
\hline $\begin{array}{l}\text { Anatomical or functional } \\
\text { asplenia }\end{array}$ & $\begin{array}{l}\text { Quadrivalent conjugate vaccine } \\
\text { (MCV4) }\end{array}$ & Recommended & $\begin{array}{l}\text { Two-dose primary schedule } \\
12 \text { weeks apart }\end{array}$ & Booster every 5 years \\
\hline HIV infection & $\begin{array}{l}\text { Quadrivalent conjugate vaccine } \\
\text { (MCV4) }\end{array}$ & Should be considered & $\begin{array}{l}\text { Two-dose primary schedule } \\
12 \text { weeks apart }\end{array}$ & Booster every 5 years \\
\hline $\begin{array}{l}\text { Other immunocompromising } \\
\text { conditions }\end{array}$ & $\begin{array}{l}\text { Quadrivalent conjugate vaccine } \\
\text { (MCV4) }\end{array}$ & Should be considered & $\begin{array}{l}\text { Two-dose primary schedule } \\
12 \text { weeks apart }\end{array}$ & Booster every 5 years \\
\hline
\end{tabular}


Hindu pilgrims of the Kumbh Mela festival to the river Ganges, India should consider vaccination with MCV4 prior to commencing their travel.

Persons with terminal complement deficiency and those with functional or anatomical asplenia are recommended to be vaccinated with MCV4. A two-dose primary schedule is suggested, followed by a booster dose every 5 years.

Individuals with HIV or other immunocompromising conditions should consider vaccination with MCV4. A two-dose primary schedule is recommended to increase the likelihood of attaining a sufficient primary immune response in these persons followed by regular booster doses. HIV-infected individuals should ideally be vaccinated before their CD4 cell count reduces to $<25 \%$.

Vaccination with a single dose of MCV4 should be considered following an outbreak of meningococcal disease due to serogroup $\mathrm{A}, \mathrm{C}, \mathrm{W}$ or $\mathrm{Y}$ in a well-defined institutional or community setting, following initial chemoprophylaxis, in order to extend protection.

The quadrivalent conjugate vaccines can be administered in conjunction with other childhood immunisations and are safe for use during pregnancy. ${ }^{21}$

There is very limited use for the polysaccharide meningococcal vaccine, viz. in individuals $>55$ years of age, if they do not have recurrent risk of meningococcal disease. However, if their risk of meningococcal disease is known to persist for $>5$ years, it may be best to use MCV4 first and then boost with either MPSV4 or MCV4 should further boosting doses be required. Either MPSV4 or MCV4 can be used in outbreak settings due to serogroups $A, C$, $\mathrm{W}$ or $\mathrm{Y}$ where the risk is not recurrent.

\section{Vaccine funding options}

At present, only the quadrivalent polysaccharide vaccine (MPSV4) is available through the public sector to those at high risk of contracting meningococcal disease, viz. for well-defined populations during outbreaks and to travellers to hyperendemic areas.

The conjugated polysaccharide vaccines (MCV4) are available through private pharmacies when prescribed by a doctor; however, funding for this comes from the patients themselves or through their private medical savings plan.

\section{Conclusion}

Although meningococcal disease incidence in South Africa is low, N. meningitidis causes severe disease that is often lifethreatening or with long-term disabilities. A quadrivalent protein conjugated meningococcal vaccine is available, and provides protection against $75 \%$ of the disease causing serogroups in South Africa.

We advise vaccination of persons at high risk of meningococcal disease including those with complement deficiency and asplenia; laboratory personal from reference labs who work with Neisseria meningitidis; and travellers or Hajj pilgrims to Saudi Arabia.

We recommend that clinicians should consider vaccination of healthy infants and children from 9 months to 5 years of age; first-year students attending college/university/military academies; miners; and those infected with HIV.
Where possible, quadrivalent conjugate meningococcal vaccines are preferable to polysaccharide vaccines given their ability to induce immune memory, allow for booster responses and eliminate carriage of the organism in the person vaccinated.

Conflict of interest statement - SM has received research funding from Sanofi Pasteur; GH has none to declare; PJ has received honoraria from Pfizer for talks on childhood pneumonia; SP has received honoraria from Pfizer for talks and received financial assistance from Sanofi to attend travel medicine conferences; AvG has received research funding from Pfizer and reimbursement of travel expenses for educational and advisory meetings for Pfizer and Sanofi.

Financial support - No financial support was awarded for the completion of this manuscript.

Acknowledgements - The contents of these recommendations were reviewed and supported by the following individuals and organisations:Lee Baker (SASTM); Simon Strachan (PMG); Kerrigan McCarthy (NICD); Chetna Govind (SASCM); Saber Yezli (Saudi Arabia Ministry of Health); National Advisory Group on Immunisation; Tsakani Furumele (CDC-Department of Health, South Africa)

\section{Note}

'C18 Microbiology laboratory, Groote Schuur Hospital, Angio Road, Observatory, 0214045540 (w).

\section{References}

1. Mandell GL, Bennett JE, Dolin R. Principles and Practice of Infectious Diseases. 7th ed. Churchill Livingstone; 2010. 4320 p.

2. Hill DJ, Griffiths NJ, Borodina E, et al. Cellular and molecular biology of Neisseria meningitidis colonization and invasive disease. Clin Sci. 2010;118(9):547-64. doi:10.1042/CS20090513.

3. MacLennanJ,KafatosG,NealK,etal.Social behaviorandmeningococcal carriage in British teenagers. Emerg Infect Diseases 2006;12(6):950-7. https://doi.org/10.3201/eid1206.051297

4. Cartwright KA, Stuart JM, Jones DM, et al. The Stonehouse survey: nasopharyngeal carriage of meningococci and Neisseria lactamica. Epidemiol Infect. 1987;99(3):591-601. https://doi.org/10.1017/S0950268800066449

5. MenAfriCar c. The diversity of meningococcal carriage across the African meningitis belt and the impact of vaccination with a group a meningococcal conjugate vaccine. J Infect Diseases 2015;212(8):1298-307. doi:10.1093/infdis/jiv211

6. Goldschneider I, Gotschlich EC, Artenstein MS. Human immunity to the Meningococcus: II. Development of natural immunity. J Exp Med. 1969;129(6):1327-48. https://doi.org/10.1084/jem.129.6.1327

7. Sadarangani M, Scheifele DW, Halperin SA, et al. Outcomes of invasive meningococcal disease in adults and children in Canada between 2002 and 2011: a prospective cohort study. Clin Infect Diseases 2015;60(8):e27-e35. doi:10.1093/cid/civ028.

8. Numanoglu A, Bickler SW, Rode $\mathrm{H}$, et al. Meningococcal septicaemia complications involving skin and underlying deeper tissues-management considerations and outcome. S Afr J Surg. 2007;45(4):142-6.

9. Stein-Zamir C, Shoob H, Sokolov I, et al. The clinical features and long-term sequelae of invasive meningococcal disease in children. Pediatric Infect Disease J. 2014;33(7):777-9. doi:10.1097/ INF.0000000000000282.

10. Simmons RD, Kirwan P, Beebeejaun K, et al. Risk of invasive meningococcal disease in children and adults with HIV in England: a population-based cohort study. BMC Med. 2015;13(1):B26. doi:10.1186/s12916-015-0538-6.

11. Cohen C, Singh E, Wu HM, et al. Increased incidence of meningococcal disease in HIV-infected individuals associated with higher casefatality ratios in South Africa. AIDS. 2010;24(9):1351-60. doi:10.1097/ QAD.0b013e32833a2520. 
12. Owen EP, Leisegang F, Whitelaw A, et al. Complement component C5 and $\mathrm{C} 6$ mutation screening indicated in meningococcal disease in South Africa. S Afr Med J 2012;102(6):525-7.

13. Meiring S, Cohen C, de Gouveia L, et al. A decade of invasive meningococcal disease surveillance in South Africa: 2003-2012. International Conference of Infectious Diseases 16th Cape Town, South Africa: International Journal of Infectious Diseases 2014. p. 21.010 .

14. von Gottberg A, du Plessis M, Cohen $C$, et al. Emergence of endemic serogroup W135 Meningococcal disease associated with a high mortality rate in South Africa. Clin Infect Diseases 2008;46(3):377-86. doi:10.1086/525260.

15. Khatami A, Pollard AJ. The epidemiology of meningococcal disease and the impact of vaccines. Expert Rev Vaccines. 2010;9(3):285-98. doi:10.1586/erv.10.3.

16. Block SL, Christensen S, Verma B, et al. Antibody persistence 5 years after vaccination at 2 to 10 years of age with Quadrivalent MenACWYCRM conjugate vaccine, and responses to a booster vaccination. Vaccine. 2015;33(18):2175-82. doi:10.1016/j.vaccine.2015.02.049.

17. Cohn AC, MacNeil JR, Clark TA, et al. Prevention and control of meningococcal disease:recommendations of the Advisory Committee on Immunization Practices (ACIP). MMWR Recommendations and reports : Morbidity and mortality weekly report Recommendations and reports / Centers for Disease Control. 2013;62(RR-2):1-28.

18. Siberry GK, Warshaw MG, Williams PL, et al. Safety and immunogenicity of quadrivalent meningococcal conjugate vaccine in 2- to 10-year-old human immunodeficiency virus-infected children. Pediatric Infect Disease J. 2012;31(1):47-52. doi:10.1097/INF.0b013e318236c67b.

19. Siberry GK, Williams PL, Lujan-Zilbermann J, et al. Phase I/II, open-label trial of safety and immunogenicity of meningococcal (Groups A, C, Y, and $\mathrm{W}$-135) polysaccharide diphtheria toxoid conjugate vaccine in human immunodeficiency virus-infected adolescents. Pediatric Infect Disease J. 2010;29(5):391-6. doi:10.1097/INF.0b013e3181c38f3b.

20. Velentgas $P, A$ mato $A A, B o h n ~ R L$, et al. Risk of Guillain-Barré syndrome after meningococcal conjugate vaccination. Pharmacoepidemiology Drug Saf. 2012;21(12):1350-8. doi:10.1002/pds.3321.
21. Pina LM, Bassily E, Machmer A, et al. Safety and immunogenicity of a quadrivalent meningococcal polysaccharide diphtheria toxoid conjugate vaccine in infants and toddlers: three multicenter phase III studies. Pediatric Infect Disease J. 2012;31(11):1173-83. doi:10.1097/ INF.0b013e318268dfe4.

22. Isaacs D. Infectious risks associated with biologics. Adv Exp Med Biol. 2013;764:151-8. https://doi.org/10.1007/978-1-4614-4726-9

23. Lewis LA, Ram S. Meningococcal disease and the complement system. Virulence. 2014;5(1):98-126. doi:10.4161/viru.26515.

24. Boutet R, Stuart JM, Kaczmarski EB, et al. Risk of laboratory-acquired meningococcal disease. J Hosp Infect. 2001;49(4):282-4. doi:10.1053/ jhin.2001.1084.

25. Nelson SJ, Charlett A, Orr HJ, et al. Risk factors for meningococcal disease in university halls of residence. Epidemiol Infect. 2001;126(2):211-7.

26. Wilder-Smith A, Memish Z. Meningococcal disease and travel. Int J Antimicrobial Agents 2003;21(2):102-6. https://doi.org/10.1016/ S0924-8579(02)00284-4

27. Department of Health. Guidelines for the management, prevention and control of meningococcal disease in South Africa. 2011 [cited 2017 Jul 10]. Available from: https://www.medbox.org/southafrica/guidelines-for-the-management-prevention-control-ofmeningococcal-disease-in-south-africa/preview?q=

28. Davison KL, Andrews N, White JM, et al. Clusters of meningococcal disease in school and preschool settings in England and Wales: what is the risk? Arch Disease Childhood 2004;89(3):256-60. https://doi.org/10.1136/adc.2003.031369

29. The Kingdom of Saudi Arabia, Ministry of Health. Hajj Health Regulations - Meningococcal Meningitis 1437 [cited 2017 Jul 10]. Available from: https://www.moh.gov.sa/en/Hajj/HealthGuidelines/ HealthGuidelinesDuringHajj/Pages/MeningococcalMeningitis.aspx

Received: 10-05-2017 Accepted: 24-07-2017 